\title{
The partitioning of food resources between two rodents in the subtropical region of southern Brazil
}

\author{
FÁBIO P. ESPINELLI ${ }^{1}$, FABIANO CORRÊA ${ }^{2}$, ELTON P. COLARES ${ }^{1}$ and IONI G. COLARES ${ }^{1}$ \\ ${ }^{1}$ Programa de Pós-Graduação em Biologia de Ambientes Aquáticos Continentais, Instituto de Ciências Biológicas/ \\ ICB, Universidade Federal do Rio Grande/FURG, Av. Itália Km 8, 96203-900 Rio Grande, RS, Brazil \\ ${ }^{2}$ Laboratório de Ictiologia, Universidade Federal de Pelotas/UFPEL, Campus \\ Universitário, s/n, 96160-000 Capão do Leão, RS, Brazil
}

Manuscript received on July 28, 2016; accepted for publication on October 7, 2016

\begin{abstract}
The capybara (Hydrochoerus hydrochaeris) and nutria (Myocastor coypus) are herbivorous semi-aquatic rodents. Although these rodents occur in sympatry in southern South America, little is known about how the two species interact in relationship to food resources. In this context, the aim of this study was to analyze the food resource overlap, the feeding strategy and the diversity of the diet of capybaras and nutria. A micro-histological analysis of feces was used to study the diets. A total of 48 plant species belonging to 10 families were identified in the diet of $H$. hydrochaeris, and a total of 49 species belonging to 14 families were identified in the diet of M. coypus. According to the Amundsen graphical method, both rodents adopted a specialized strategy for feeding on Poaceae and a generalized strategy for other families. The results of a multivariate analysis of the dietary data showed significant differences between the two rodent species and among the seasons. These differences between diets may be related to the different proportions of each food item eaten. However, the dietary overlap between the two rodents in the Taim wetland was high, suggesting that partitioning of other resources ensured the coexistence of the species.
\end{abstract}

Key words: diet overlap, feeding strategy, herbivores, micro-histological analysis.

\section{INTRODUCTION}

According to optimal foraging theory, decisions by feeding herbivores are based on the need to maximize the forager's energy balance (Townsend et al. 2006). However, the energy quality of the diet is extremely variable, as herbivores tend to select plants with specific nutrients or even to avoid various toxins (Dumont 1997). The acquisition of food is an important aspect of the behavior of

Correspondence to: Fábio Penna Espinelli

E-mail: pennaespinelli@yahoo.com.br individuals (Krebs and Davies 1987). In particular, herbivores dedicate a large part of their time to foraging, and this activity can be influenced by other factors, such as competition. According to Quintana (2002), the proximity of predators and specific physical and physiological characteristics of the plant species consumed tend to influence the pattern of food competition. In fact, the use of food resources by a community assists in the understanding of intra- and interspecific trophic interactions, which provide information relevant to understanding the feeding ecology, conservation 
and management of species (Quintana et al. 1998). The maintenance of the diversity of coexisting species is often interpreted as the result of niche differentiation. Most of the arguments that invoke resource partitioning to explain the diversity of species assume that the environment is heterogeneous, favoring the coexistence of different competitors (Bazzaz and Catovsky 2001).

The coexistence of species in a region may result in niche overlap on a spatiotemporal scale. Niche overlap becomes possible because species have different needs as consumers of food resources and are specialized for success in harvesting different sets of resources in certain geographical areas (Pianka 1974, Schoener 1974, Bazzaz and Catovsky 2001). The term "resource partitioning" may be defined as the differential use of resources by different organisms, such as food and space (Schoener 1974, Begon et al. 1990). This concept attempts to explain how species coexist despite broadly overlapping ecological requirements (May and MacArthur 1972).

The capybara Hydrochoerus hydrochaeris (Linnaeus 1766) and nutria Myocastor coypus (Molina 1978) are large semi-aquatic rodents. The capybara ranges from Panama to Uruguay, with its distribution extending to northwestern Argentina (Emmons 1990), while the nutria is native to southern South America (Borgnia et al. 2000). Both species coexist in the southern subtropical region in diverse habitats, such as swamps, lagoons, and estuaries (Achaval et al. 2004), even in humaninfluenced areas with high human interference. The capybara feeds on grasses, sedges and aquatic plants having a high protein content (Ojasti 1973, Escobar and González-Jiménez 1976). The nutria feeds on herbaceous roots and aquatic plants (Abbas 1991, Borgnia et al. 2000, Prigioni et al. 2005). This information suggests that both species have similar diets, resulting in competition or even dietary overlap. However, it is necessary to define the diets of the species under study before evaluating competition or dietary overlap. Three methods of dietary assessment are used in studies of the feeding ecology of herbivorous mammals: direct observation of animals in the field (Barreto and Herrera 1998, Forero-Montaña et al. 2003, Prigioni et al. 2005), analysis of stomach contents (Gayot et al. 2004) and analysis of fecal samples (Abbas 1991). Quintana and Rabinovich (1993) have suggested that the collection of feces is the most practical way to achieve rapid, simple and economical dietary sampling. In addition, this approach provides an unlimited number of samples and eventually allows the comparison of the diet of two or more animals inhabiting a given area at the same time (Quintana et al. 1994).

Morphological similarities tend to increase competition among species. By hypothesis, it is expected that coexisting species of rodents will explore the available spectrum of food resources. Several studies on the feeding habits of the capybara and nutria in their natural habitat have been conducted (Ojasti 1973, Escobar and GonzálezJiménez 1976, Quintana et al. 1994, 1998, Borgnia et al. 2000, Quintana 2002, Guichón et al. 2003a, Borges and Colares 2007, Aldana-Domínguez et al. 2007, Colares et al. 2010, Desbiez et al. 2011). However, no previous integrative study has investigated the diet of these two species in the Taim wetland, located in subtropical southern Brazil.

Within this context and based on the feeding habits of the capybara and nutria, this paper aims to answer the following questions: Are the frequencies of consumption of food items by the two species of rodents similar? Are the feeding strategies of the two species similar? Are there differences in dietary diversity between the two species? Does temporal dietary overlap occur between the species? The answers to these questions will provide information about aspects of the distribution of the food resources of these rodents in this important wetland area in southern Brazil. 


\section{MATERIALS AND METHODS}

The Taim wetland is located in southern Brazil between Lagoa Mirim and the Atlantic Ocean (Fig. 1). Its climate is Cfa (humid temperate) according to the Köppen classification and is characterized by cold and rainy winters and hot summers. The average annual precipitation is $1,100 \mathrm{~mm}$, and the average temperature is $18^{\circ} \mathrm{C}$ (Nimer 1989). The Taim wetland is crossed by highway BR-471, built in the 1950's. Parallel to the road, on its west side, is an artificial waterway. The waterway is located at $32^{\circ} 33^{\prime} \mathrm{S} / 52^{\circ} 34^{\prime} \mathrm{W}$. This waterway was built to allow the removal of sand for construction of the road and extends west to the Mirim. The vegetation on the banks of the waterway is dominated by native grasses and other herbaceous plants, such as Setaria geniculata and Eleocharis bonariensis, respectively.

Sampling of vegetation and feces was conducted during one year, between August 2012 and July 2013. Sampling of flora was conducted seasonally, and sampling of feces was performed monthly. Feces and vegetation were collected along a linear transect $6 \mathrm{~km}$ long with a width of $5 \mathrm{~m}$ measured from the edge of the waterway west of the road. The vegetation was collected by the traversal method, labeled and subsequently transferred to the laboratory, where the samples were identified and deposited in the collection of the University of Rio Grande Herbarium (HURG). Species identification was based on the technical literature, with assistance from specialists if necessary (FURG). The arrangement of families of angiosperms was based on the Angiosperm Phylogeny Group classification (APG III 2009), and the pteridophytes were classified according to Smith et al. (2006). Plants were collected to determine the diversity of plant species available to the capybara and the nutria.

The collected fecal samples were stored in $50 \mathrm{ml}$ Falcon tubes containing a solution of $85 \%$ ethanol, $10 \%$ formol at $10 \%$ and $5 \%$ acetic acid (FAA). For each fecal sample stored in FAA, three

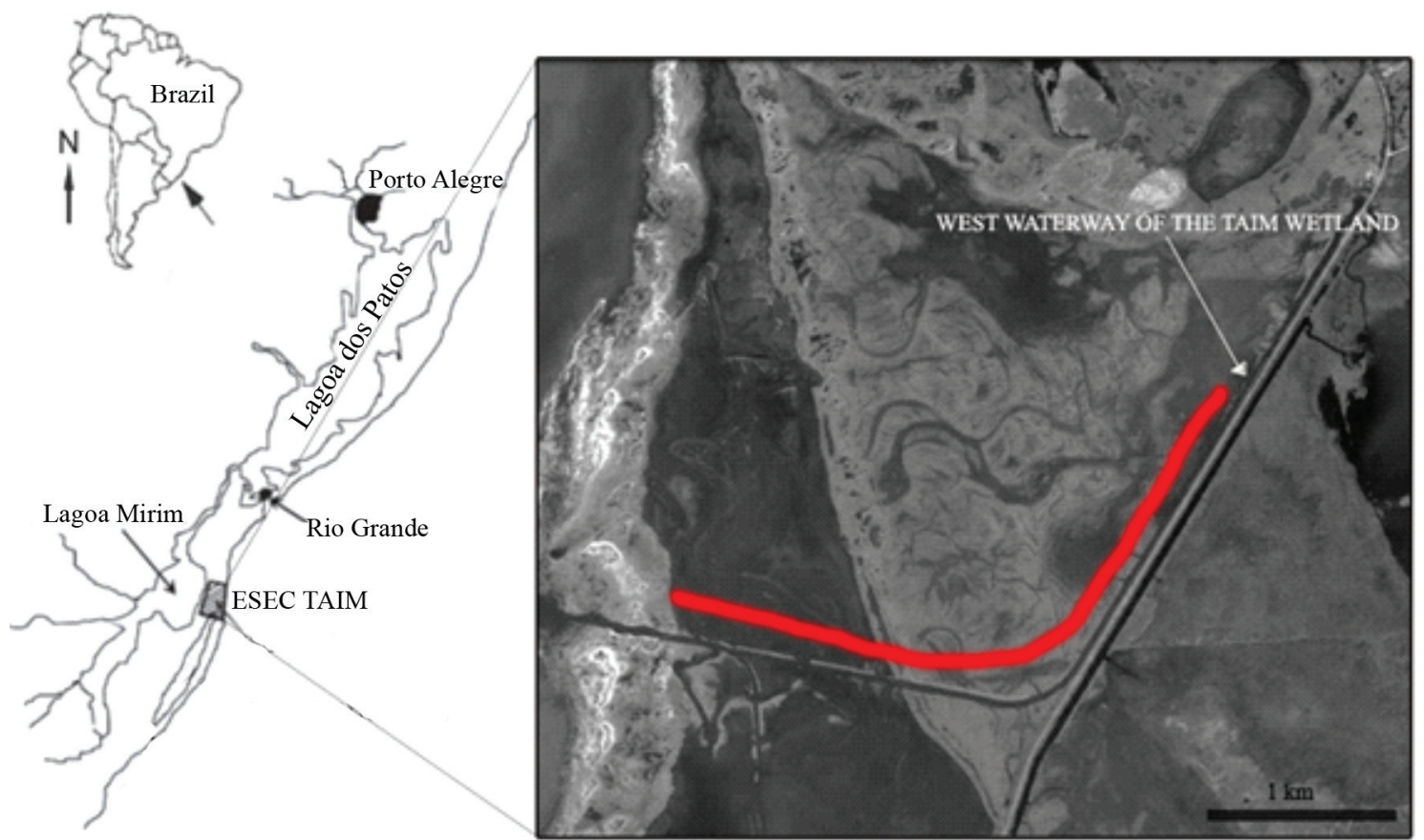

Figure 1 - Location of the area of data collection represented by red line, the west waterway of the Taim wetland, south of Brazil (see the colors in the online version). 
subsamples were diluted in distilled water, and all three subsamples were mounted on microscope slides. All samples had previously been cleared with 10\% sodium hypochlorite (Santos et al. 2010). The plant species were identified to the lowest possible taxonomic level based on anatomical characteristics such as the size, the shape and type of stomata, and the types and sizes of trichomes and the presence of solid inclusions (Santos et al. 2010).

Food items found in the fecal content of individuals were identified based on an examination of the entire surface of the microscopic slides with an optical microscope at $20 \mathrm{X}$ magnification. The species present were identified using the plant epidermis reference collection at the Institute of Biological Sciences (ICB), Federal University of Rio Grande - FURG and with the aid of a specialized bibliography (Santos et al. 2010). For each food item found, the following parameters were measured: a) the frequency of occurrence (FO\%), which corresponds to the percentage of the total number of samples in which a food item is found, and $b$ ) the numerical abundance ( $\mathrm{N} \%)$, which corresponds to the percentage of numerical abundance of fragments of a given food item for all items present (Abbas 1991). The FO\% and N\% data were combined in an alimentary index (IAi) modified from Kawakami and Vazzoler (1980):

$$
I A i=\frac{F o_{i} \times N_{i}}{\sum F o \times N} \times 100
$$

For each species of rodent, the feeding strategy was calculated with the graphical method of Amundsen et al. (1996), for which food items were grouped by families, according to the formula $\mathrm{Pi}=\%(\Sigma \mathrm{Si} / \Sigma \mathrm{Sti}) \times 100$, where $\mathrm{Si}=$ number of samples containing only items belonging to family $\mathrm{i}$ and $\mathrm{Sti}=$ total number of samples in which items belonging to family i occur. Patterns of dietary overlap of species were calculated using the index of Pianka (1974), with values ranging from zero (no dietary overlap) to 1 (total dietary overlap) and obtained from the formula

$$
O_{12}=\frac{\sum_{i=1} P_{i 2} \times P_{i 1}}{\sqrt{\sum_{i=1}\left(P_{i 2}^{2}\right) \times\left(P_{i 1}^{2}\right)}}
$$

where $\mathrm{O}_{12}=$ measure of dietary overlap between species 1 and 2, $\mathrm{P}_{\mathrm{i} 2}$ and $\mathrm{P}_{\mathrm{i} 1}$ represent the proportional abundance of the plant species used by species 1 and 2 , and $\mathrm{n}$ is the total number of items. Based on the value of dietary overlap, a null model was applied to assess the statistical significance of the dietary overlap between the capybara and the nutria (Winemiller and Pianka 1990). To estimate the dietary overlap of the patterns of use of the food items, the RA3 randomization algorithm was used. For this model, the values of IAi for the food items were randomized 5000 times, and the statistical significance was determined based on a comparison with the mean dietary overlap and the null distribution, with a significance value of $p$ $<0.05$ (Winemiller and Pianka 1990). Ecosim 7.2 software (Gotelli and Entsminger 2011) was used for the calculation of the null model. The Shannon diversity index ( $\left.\mathrm{H}^{\prime}\right)$ was used to determine the diversity of the number of species in the diet of both rodents.

A PERMANOVA permutation analysis was applied to evaluate the statistical significance of differences between species and among seasons. For the PERMANOVA test, the null hypothesis was that there was no significant difference between species. The hypothesis was rejected at a level of significance of $\mathrm{p}<0.05$ (Clarke and Gorley 2006). An input matrix of the square-roottransformed values of abundance of the food items using the Bray-Curtis index was analyzed for this purpose. The level of significance was analyzed using 10,000 permutations of the groups. Food 
items with an abundance of less than five fragments for both species were excluded from this analysis. To evaluate which food item made the highest contribution to the differentiation between the species, an analysis of the percentage of minimum similarity (SIMPER) was applied.

\section{RESULTS}

A total of 142 plant species belonging to 36 families and 99 genera were identified in the environment. A total of 220 samples of feces were collected, 120 from capybara and 100 from nutria, of which 10 samples were analyzed randomly per station for each species. The Shannon dietary diversity ( $\left.\mathrm{H}^{\prime}\right)$ differed significantly between the two species ( $p$ $=0.04)$. The microhistological examination of the feces showed that the consumption of aquatic plants (H. hydrochaeris 54\%, M. myocastor 60\%) was greater than the consumption of terrestrial plants $(\mathrm{p}=0.05)$.

A total of 17,301 fragments of plant epidermis were identified in the diet of $H$. hydrochaeris. These fragments represented 48 plant species belonging to 10 families. Among the identified plants, there was a predominance of species of the family Poaceae $(\mathrm{IAi}=81.9 \%)$, followed by Cyperaceae (IAi $=17.1 \%$ ). The main food items consumed by H. hydrochaeris were Eleocharis bonariensis (IAi $=15.8 \%$ ), with a high frequency of occurrence $(\mathrm{FO}=80.0 \%)$, and Paspalum distichum (IAi $=$ $10.8 \%$ ), also with a high frequency of occurrence $(\mathrm{FO}=80.0 \%)$. The IAi values for the remaining food items ranged from $10.6 \%$ to $3.7 \%$ (Table SI Supplementary Material).

For M. coypus, 16,311 fragments of plant epidermis were identified, representing 49 plant species belonging to 14 families. The microhistological analysis of the feces showed that the diet consisted primarily of Poaceae (IAI $=88.5 \%)$ and Cyperaceae $(\mathrm{IAi}=9.17 \%)$. The principal food items consumed by $M$. coypus were Echinochloa polystachya $(\mathrm{IAi}=18.8 \%)$, with a high frequency of occurrence $(\mathrm{FO}=87.5 \%)$, and Paspalum vaginatum (IAi $=17.7 \%$ ), also with a high frequency of occurrence $(\mathrm{FO}=85.00 \%)$. The IAi values for the remaining food items ranged from $13.84 \%$ to $3.69 \%$ (Table SI). When the food items were grouped into families, the Poaceae were dominant, with 25 species in the diet of both rodents, followed by the Cyperaceae, with 10 species in the diet of H. hydrochaeris and six species in the diet of $M$. coypus. The graphical method of Amundsen showed that the rodents were dietary specialists on Poaceae and dietary generalists on other families (Fig. 2). Poaceae was the dominant family in terms of food items for H. hydrochaeris and M. coypus, with an abundance of specific prey (AEP) of $81.1 \%$ and $84.8 \%$, respectively. The dietary overlap between $H$. hydrochaeris and $M$. coypus was $\mathrm{O}_{12}=$ $0.72(\mathrm{p}=0.001)$, primarily due to the consumption of Eleocharis bonariensis and Paspalum distichum.

The food items consumed by the two rodents differed significantly among the seasons. The PERMANOVA indicated a difference in diet between species $(\mathrm{F}=3.53, \mathrm{p}=0.02)$ and among stations (pseudo-F $=6.91, p=0.0001$ ), but there was no interaction (pseudo-F $=0.91, p=0.5$ ). The SIMPER analysis showed a $72.16 \%$ dissimilarity between species, with the largest contribution from E. bonariensis (6.54\%), followed by L. peruviana $(5.97 \%)$ and E. polystachya $(5.25 \%)$. The food diversity did not differ significantly among seasons for the rodent species. However, H. hydrochaeris showed a significant difference between spring and summer $(\mathrm{p}=0.01)$ (Table SII).

The greatest food diversity observed in the diet of both rodents was in the summer, whereas the lowest diversity was observed during the spring and fall. In the diet of $H$. hydrochaeris, E. bonariensis (Cyperaceae) was dominant in winter and autumn (IAi $=21.5 \%$ and $21.2 \%$, respectively). For $M$. coypus, E. polystachya (Poaceae) was dominant in spring and summer (IAi $=27.5 \%$ and $23.8 \%$, respectively) (Table SII). According to the null 
model, winter was the season of the greatest dietary

the lowest dietary overlap was observed in the fall overlap $(86.4 \%)$ between the two rodents, whereas (51.7\%) (Fig. 3).
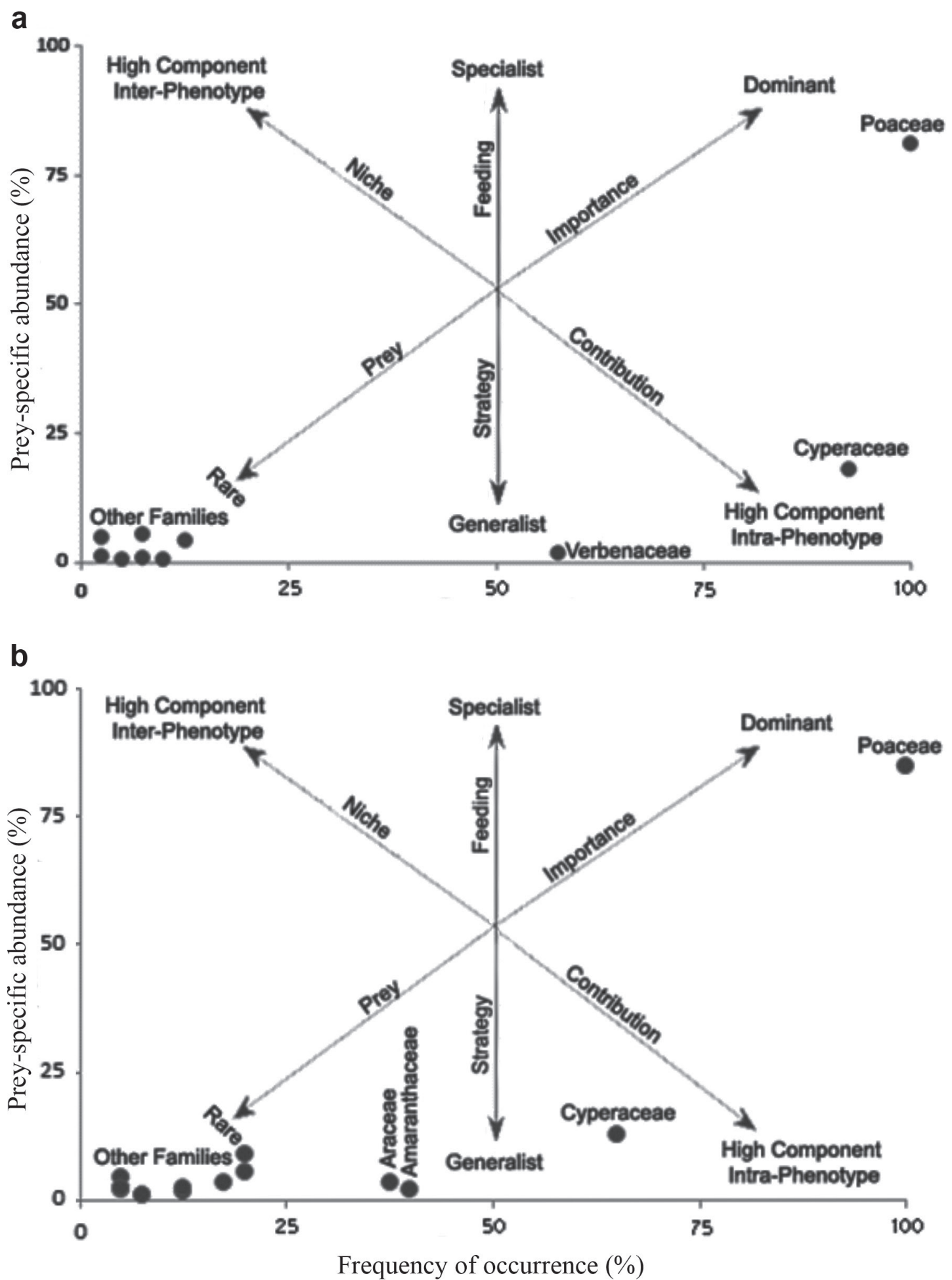

Figure 2 - Feeding strategy showing the graphical relationship between the frequency of occurrence and abundance of specific prey in the capybara (a) and nutria diet (b), in the Taim wetland, south of Brazil. 


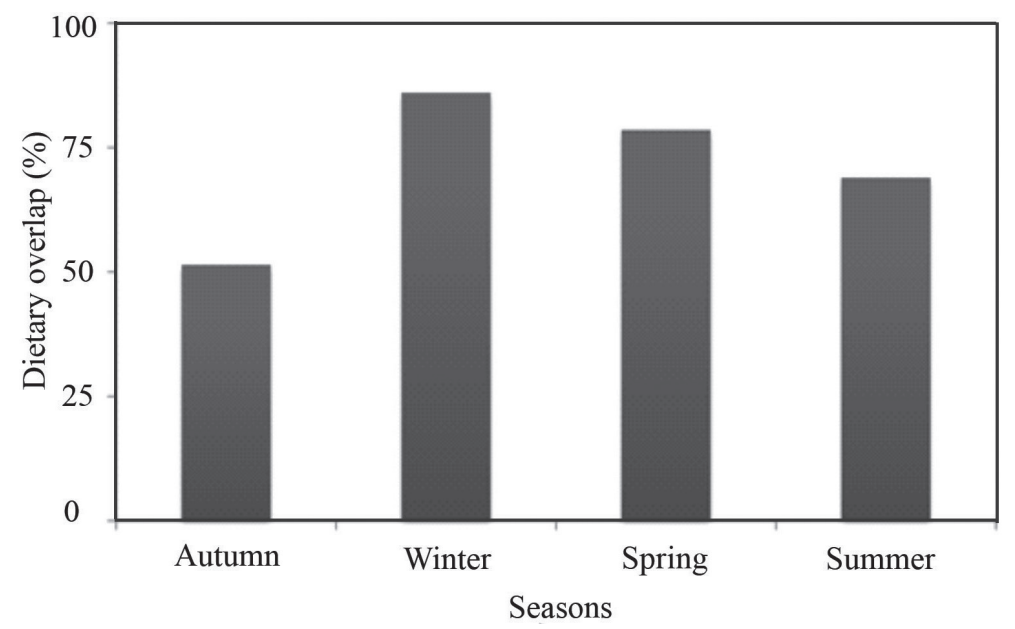

Figure 3 - Dietary overlap in capybara and nutria in the year of study seasons, in the Taim wetland, south of Brazil.

An analysis of the diet of the two rodents for each family of plants in different seasons showed that Poaceae and Cyperaceae had the highest food abundance and importance. Poaceae had a greater food importance in the diet of $H$. hydrochaeris during summer $(\mathrm{IAi}=96.4 \%)$ and a greater food importance in the diet of $M$. coypus during autumn $(\mathrm{IAi}=96.1 \%)$, whereas the food importance of Cyperaceae was lower for both species (Table SII).

\section{DISCUSSION}

The coexistence of species in a given region may result in the spatiotemporal partitioning of food resources as a result of the overlapping ecological and behavioral needs of each species (May and MacArthur 1972). Although it is related to the semi-aquatic habit of these animals, the higher frequency of occurrence of the identified aquatic plants in the diet of H. hydrochaeris and M. coypus, in the Taim wetland can characterize an overlap in the use of food resources for each species. Furthermore, the occurrence of foraging behavior near bodies of water reinforces the hypothesis that behavior serves as a mechanism to reduce the risk of predation and to maintain body temperature (Guichón et al. 2003b). Both species showed the same pattern of habitat occupancy and food choice.
Similar results have been obtained by other studies showing that the aquatic vegetation observed in the diet of the two rodents was associated with the semi-aquatic habits of these animals (Desbiez et al. 2011, Galende et al. 2013).

Herbivores generally select a diet according to the environmental characteristics and peculiarities of each region (Prigioni et al. 2005). The analysis of the diet of $H$. hydrochaeris and $M$. coypus in the Taim wetland showed no numerical variation in the number of ingested species. However, both diets had a higher level of species diversity than that found by previous studies in southern Brazil (Borges and Colares 2007, Colares et al. 2010). Despite the wide range of food items available to the two species of rodents, only a portion of the available items was consumed by both species. Both availability and diversity of food resources may have been a major factor in this difference because the samples from our study area cover different environments in the Taim wetland, representing a greater diversity in the food supply.

The dietary similarity between the two rodents is evident from the consumption of Poaceae, especially Paspalum distichum and Echinochloa polystachya, which occurred at high frequencies in the diets of H. hydrochaeris and M. coypus, 
respectively. The importance of Poaceae in the diet of the two rodents is reinforced by the analysis of the feeding strategies of the species. The Amundsen graph shows a clear trend toward specialization for the consumption of Poaceae. Consistent with the results of the present study, previous research has also highlighted the importance of Poaceae in the diet of both H. hydrochaeris (Quintana 2002, Forero-Montaña et al. 2003, Borges and Colares 2007, Desbiez et al. 2011) and M. coypus (Borgnia et al. 2000, Colares et al. 2010).

Although the consumption of plant species belonging to the Poaceae was similar between the two rodent species, the species of the highest importance in the diet differed between the two rodents. The importance value of Leersia hexandra, Cynodon dactylon, Andropogon selloanus, and Luziola peruviana was high in the diet of $H$. hydrochaeris, whereas Eleocharis bonariensis, Cynodon dactylon, Paspalum vaginatum and species of the genus Echinochloa were the items with a high importance value in the diet of M. coypus. Specifically, only Cynodon dactylon showed a high importance value in the diet of both rodents. All these species have previously been reported as components of the diet of the two rodents in other areas of their natural distribution (Ojasti 1973, Escobar and González-Jiménez 1976, Quintana et al. 1998, Quintana 2002, Guichón et al. 2003a, Aldana-Domínguez et al. 2007, Desbiez et al. 2011).

Other items with a lower importance value, i.e., Alternanthera philoxeroides and Setaria geniculata in the diet of M. coypus and Alternanthera philoxeroides and Eichhornia crassipes in the diet of $H$. hydrochaeris, also indicate dietary overlap between the two rodents. These similarities between the food items and diets are most likely related to the abundance of these broadly distributed species and the dietary predation for these items by the two rodents.

In general, herbivorous mammals tend to select diets that are high in nutrients and relatively low in toxins, given the plants available for consumption (Provenza and Balph 1990). According to Corriale et al. (2011), the capybara selects food items according to their nutritional characteristics, and the energy content would be the variable that determines the preference of capybaras and the plants that are consumed in a proportion greater than their availability. Borgnia et al. (2000) attribute the selectivity of $M$. coypus to the presence or absence of secondary metabolites that can reduce the nutritional value of the ingested species. Most likely, the dietary selectivity of both rodents (Escobar and González-Jiménez 1976, Quintana et al. 1998, Quintana 2002, Guichón et al. 2003a, Borges and Colares 2007, Galende et al. 2013), the relative palatability of the plants available for foraging, and the strong relationship between energy content and fiber (Molano 1994, Colares et al. 2010) explain a number of the similarities observed between the diets of the two rodents. Another characteristic to note is the similarity of the morphology of the oral apparatus, e.g., the incisor teeth of both rodents, which can directly shape the similarity between species in the use of food resources (Croft and Niemi 2011).

Several of the statistically significant differences between the two diets can be explained by the distribution of vegetation along the gradient between the water body and drier locations or the foraging habits of each rodent. According to Aldana-Domínguez et al. (2007), capybaras require a dry resting place and different habitats to supply their needs. In contrast, nutria use terrestrial environments less frequently and tend to foraging for longer periods in the proximity of water bodies (D'Adamo et al. 2000, Borgnia et al. 2000). Thus, A. selloanus, a food item that was common in the diet of capybara $(\mathrm{FO}=67.50 \%)$, showed a much lower frequency $(\mathrm{FO}=30 \%)$ in the diet of nutria. This plant is a terrestrial species that occurs in sandy soils with a lower moisture content (Boldrini et 
al. 2008). These characteristics may limit the use of A. selloanus by nutria.

These differences between diets may also be related to the spatial distribution of individuals over the longitudinal gradient. Capybara feces were found throughout the study area, but nutria feces were found only in the last $3 \mathrm{~km}$ of the transect. As noted by Colares et al. (2010), it is probable that the availability of vegetation and, accordingly, the diets of the two rodent species can vary in different types of habitat. Note that the dietary selectivity of an animal varies with the environmental characteristics and peculiarities of each region that affect the availability of vegetation (Prigioni et al. 2005).

According to Colares et al. (2010) and Borges and Colares (2007), the diets of the two rodents change depending on the availability of food resources. Although the diets of the two rodents show a predominant use of Poaceae, other plant families were also identified in the diet, with lower levels of importance, representing a more generalized feeding strategy on the plant families that are consumed in smaller amounts. This specialization of the two rodents on Poaceae is due to the nutritional quality and availability in the environment of this family of plants (Forero-Montaña et al. 2003, Colares et al. 2010) and is in accordance with the principles of optimal foraging theory, which predict that the selected food items should have a high energy content (Chaves and Alves 2010).

Changes in the consumption of food items among seasons were observed for both $H$. hydrochaeris and M. coypus in the Taim wetland. An observed increase in the consumption of Cyperaceae was related to the increased consumption of items in the genus Eleocharis during the winter by the two rodents. Winter in the swamps of the Taim region is characterized by lower temperatures and higher rainfall (Borges and Colares 2007). Under these conditions, the availability of food items tends to decrease (Colares et al. 2010), and the ro- dents must consume the available items. Previous studies have also underscored the importance of the genus Eleocharis in the diet of capybaras during the rainy season in Venezuela (Herrera and Macdonald 1989). Food preferences by nutria have also been observed throughout the winter and spring in Argentina (Borgnia et al. 2000).

During the summer, both rodents showed a greater diversity of items consumed. As warmer seasons favor the growth of plants, food consumption increases during these seasons. Poaceae were consumed by the two rodents during the summer, but differences were found in the importance index. Andropogon selloanus was consumed more by capybaras, and Echinochloa polystachya was consumed more by nutria. Most likely, these differences were caused by differences in the composition of the local flora among seasons. Significant differences were found for the main items consumed. However, seasonal fluctuations in the diet of the two species studied may still be in accordance with adjustments of foraging effort in response to the changes in the abundance and quality of resources.

Observations made in previous studies corroborate the findings of this study that the feeding behavior of the two rodents varies with the seasons (Borgnia et al. 2000, Guichón et al. 2003a, Colares et al. 2010). According to Barreto and Quintana (2012), the consumption of certain species may be associated with periods of shortage in the supply of other food items or the local dominance of these species. These variations among locations in the items consumed are also influenced by the nutritional value of the plants. During the growing season, the plants are more palatable and higher in nutritional value (Colares et al. 2010), making them more attractive for consumption by the rodents. Such a change in nutritional value can produce a change in diet, e.g., by increasing the consumption of Cyperaceae, as observed in the Taim wetland.

Habitats and food resources can be divided among species over time (Kotler and Brown 1988). 
Note that authors such as Voeten and Prins (1999) and and Desbiez et al. (2009), in the African savannah and in the Brazilian Pantanal, respectively, have also identified seasonal differences in diet in various herbivores. Quintana et al. (1998) have emphasized that the variations in the diets of herbivores are correlated with temporal variations in climate and vegetation, noting that capybaras adapt to these changes by modifying their pattern of foraging. Corriale et al. (2011) have highlighted the importance of seasonal fluctuations in the size of the living area of groups of capybaras. These fluctuations were strongly related to the composition and abundance of vegetation and water availability. According to the study of Guichón et al. (2003a), nutria were selective in all seasons, and their diet was based almost exclusively on aquatic plants. These differences in diets between seasons may be linked to the size of populations of plant species, which vary seasonally.

Based on this study of the diet of H. hydrochaeris and $M$. coypus, we can suppose that the foraging patterns of both rodents varied seasonally, causing a high overlap in the diet of both species. This high overlap between the diets of rodents arises because the species share the same food resources available in the environment. The similarity in consumer of food resources becomes even more evident during the winter, when food is scarce and the consumption of Cyperaceae increases. Interspecific competition between sympatric herbivores presumably produces niche separation, which can occur through the differential use of plant habitat or of parts of plants (Sinclair 1985). The partitioning of resources between sympatric herbivores is commonly based on differences in feeding strategies. The high dietary overlap observed between $H$. hydrochaeris and $M$. coypus in the Taim wetland suggests that these herbivores should share other axes of their niches, such as the use of habitat resources, to minimize competition, ensuring the coexistence of both species.

\section{ACKNOWLEDGMENTS}

The authors thank the Instituto de Ciências Biológicas (ICB) of Universidade Federal do Rio Grande (FURG) and Coordenação de Aperfeiçoamento de Pessoal de Nível Superior (CAPES), for the readiness of the resources used in the execution of this work. We are grateful to Sônia Hefler and Carolina Igansi for identifying plants collected. Fieldwork was supported by ESEC Taim. We would like to thank for all that helped in both the field and the lab.

\section{REFERENCES}

ABBAS A. 1991. Feeding strategy of coypu (Myocastor coypus) in central Western France. J Zool Soc London 224: 385-401.

ACHAVAL F, CLARA M AND OLMOS A. 2004. Mamíferos de la República Oriental del Uruguay. $1^{a}$ Edición, Imprimex, Montevideo, Uruguay, $176 \mathrm{p}$.

ALDANA-DOMÍNGUEZ J, VIEIRA-MUÑOZ MI AND ÁNGEL-ESCOBAR DC (Eds). 2007. Estudios sobre la ecología del chigüiro (Hydrochoerus hydrochaeris), enfocados a su manejo y uso sostenible en Colombia. Instituto Alexander von Humboldt. Bogotá D.C., Colombia, $188 \mathrm{p}$.

AMUNDSEN PA, GABLER HM AND STALDAVIK FJ. 1996. A new approach to graphical analysis of feeding strategy from stomach contents data - modification of the Costello (1990) method. J Fish Biol 48: 607-614.

ANGIOSPERM PHYLOGENY GROUP. 2009. An update of the Angiosperm Phylogeny Group classification for the orders and families of flowering plants: APG. Bot J Lin Soc 161: 105-121.

BARRETO G AND HERRERA E. 1998. Foraging patterns of capybaras in a seasonally flooded savanna of Venezuela. J Trop Ecol 14: 87-98.

BARRETO G AND QUINTANA RD. 2012. Foraging strategies and feeding habits of capybaras. Pages 83-96. In: Moreira JR, Ferraz KMP, Herrera EA and Macdonald DW (Eds), Capybara: biology, use and conservation. Dordrecht, the Netherlands: Springer.

BAZZAZ FA AND CATOVSKY S. 2001. Resource partitioning. Encyclopedia of Biodiversity. Academic Press, San Diego.

BEGON M, HARPER JL AND TOWNSEND CR. 1990. Ecology, individuals, populations and communities. Blackwell Sc., Boston, E.E.U.U, 947 p.

BOLDRINI II, LONGHI-WAGNER HM AND BOECHAT SC. 2008. Morfologia e taxonomia de gramíneas sul-riograndenses. $2^{\mathrm{a}}$ ed., Porto Alegre, Editora UFRGS. 
BORGES LV AND COLARES IG. 2007. Feeding Habits of Capybaras (Hydrochaeris hydrochaeris, Linnaeus 1766), in the Ecological Reserve of Taim (ESEC Taim) - South of Brazil. Braz Arch Biol Techn 50(3): 409-416.

BORGNIA M, GALANTE ML AND CASSINI MH. 2000. Diet of the coypu (Nutria, Myocastor coypus) in agrosystems of Argentinean Pampas. J Wildlife Manage 64(2): 354-361.

CHAVES FG AND ALVES MAS. 2010. Teoria do Forrageamento Ótimo: Premissas e Críticas em Estudos com Aves. Oecologia Australis 14(2): 369-380.

CLARKE KR AND GORLEY RN. 2006. Primer v.6: User manual/tutorial, PRIMER-E Ltd., Plymouth UK.

COLARES IG, OLIVEIRA RNV, OLIVEIRA RM AND COLARES EP. 2010. Feeding habits of coypu (Myocastor coypus Molina 1978) in the wetlands of the Southern region of Brazil. An Acad Bras Cienc 82: 671-678.

CORRIALE MJ, ARIAS SM AND QUINTANA RD. 2011. Forage quality of plant species consumed by capybaras (Hydrochoerus Hydrochaeris) in the Paraná River Delta, Argentina. Rangeland Ecol Manag 64(3): 257-263.

CROFT DAK AND NIEMI AF. 2011. Incisor morphology reflects diet in caviomorph rodents. J Mammal 92: 871-879.

D’ADAMO P, GUICHÓN ML, BÓ RF AND CASSINI MH. 2000. Habitat use of coypus (Myocastor coypus) in agrosystems of the Argentinean Pampas. Acta Theriol 45: 2533.

DESBIEZ ALJ, SANTOS SA, ALVAREZ JM AND TOMAS WM. 2011. Forage use in domestic cattle (Bos indicus), capybara (Hydrochoerus hydrochaeris) and pampas deer (Ozotoceros bezoarticus) in a seasonal Neotropical wetland. Mamm Biol 76: 351-357.

DESBIEZ ALJ, SANTOS SA, KEUROGHLIAN A AND BODMER RE. 2009. Niche partitioning among whitelipped peccaries (Tayassu pecari), collared peccaries (Pecari tajacu), and feral pigs (Sus scrofa). J Mammal 90: 119-128.

DUMONT B. 1997. Diet preferences of herbivores at pasture. Ann Zootech 46: 105-116.

EMMONS LH. 1990. Neotropical Rainforest Mammals. A field guide. The University of Chicago Press.

ESCOBAR A AND GONZÁLEZ-JIMÉNEZ E. 1976. Estudio de la competencia alimenticia de los herbívoros mayores del Llano inundable con referencia especial al chigüiro (Hydrochaerys hydrochaeris). Agron Trop 26: 215-227.

FORERO-MONTAÑA J, BETANCUR J AND CAVELIER J. 2003. Dieta del capibara Hydrochaeris hydrochaeris (Rodentia: Hydrochaeridae) em Caño Limón, Arauca, Colômbia. Rev Biol Trop 51: 579-590.

GALENDE GI, TRONCOSO A AND LAMBERTUCCI SA. 2013. Effects of coypu (Myocastor coypus) abundances and diet select on a wetland of the Patagonian steppe. Stud Neotrop Fauna E 48: 32-39.
GAYOT M, HENRY O, DUBOST G AND SABATIER D. 2004. Comparative diet of the two forest cervids of the genus Mazama in French Guiana. J Trop Ecol 20: 31-43.

GOTELLI NJ AND ENTSMINGER GL. 2011. EcoSim: Null models software for ecology. Version 7. Acquired Intelligence Inc. And Kesey-Bear. Jericho, VT 05465.

GUICHÓN ML, BENÍTEZ VB, ABBA SA, BORGNIA M AND CASSINI ML. 2003a. Foraging behavior of coypus Myocastor coypus: why do coypus consume aquatic plants? Acta Oecol 24: 241-246.

GUICHÓN ML, BORGNIA M, RIGHI CF, CASSINI GH AND CASSINI MH. 2003b. Social behavior and group formation in the coypu (Myocastor coypus) in the Argentinean Pampas. J Mammal 84: 254-262.

HERRERA EA AND MACDONALD DW. 1989. Resource utilization and territoriality in group-living capybaras (Hydrochoerus hydrochaeris). J Anim Ecol 58: 667-679.

KAWAKAMI E AND VAZZOLER G. 1980. Método gráfico e estimativa de índice alimentar aplicado no estudo de alimentação de peixes. Bol Inst Oceanogr 29(2): 205-207.

KOTLER BP AND BROWN JS. 1988. Evironmental heterogeneity and the coexistence of desert rodents. Annu Rev Ecol Syst 19: 281-307.

KREBS JR AND DAVIES NB. 1987. An Introduction to Behavioural Ecology. $2^{\text {nd }}$ edition. Blackwell Scientific Publication, Oxford.

MAY RM AND MACARTHUR RH. 1972. Niche Overlap as a Function of Environmental Variability. Zoology 69(5): 1109-1113.

MOLANO F. 1994. Utilización del chigüiro (Hydrochoerus hydrochaeris), en el desarrollo de un sistema de producción sostenible para el Área de Manejo Especial en La Macarena. Informe presentado al Ministerio de Agricultura (Pronata), Bogotá, Colombia, p. 47-75.

NIMER E. 1989. Climatologia do Brasil. Rio de Janeiro: IBGE/SUPREN.

OJASTI J. 1973. Estudio biologico del chigüire o capibara. Caracas, Ed. Fondo Nacional de Investigaciones Agropecuarias.

PIANKA E. 1974. Niche overlap and diffuse competition. P Natl Acad Sci USA 71: 2141-2145.

PRIGIONI C, BALESTRIERI A AND REMONTI L. 2005. Food habits of the coypu, Myocastor coypus, and its impact on aquatic vegetation in a freshwater habitat of NW Italy. Folia Zool 54(3): 269-277.

PROVENZA FD AND BALPH DF. 1990. Applicability of five diet-selection models to various foraging challenges ruminants encounters. In: Hughes RN (Ed), Behavioural Mechanisms of Food Selection. Series G: Ecological Sciences, Springer, Berlin 20: 423-459.

QUINTANA RD. 2002. Influence of livestock grazing on the cabybara's trophic niche and forage preferences. Acta Theriol 47(2): 175-183. 
QUINTANA RD, MONGE S AND MALVÁREZ AI. 1994. Feeding-habits of capybara (Hydrochaeris hydrochaeris) in afforestation areas of the lower delta of the Paraná River, Argentina. Mammalia 58(4): 569-580.

QUINTANA RD, MONGE S AND MALVÁREZ AI. 1998. Feeding patterns of capybara Hydrochaeris hydrochaeris (Rodentia, Hydrochaeridae) and cattle in non-insular area of the Lower delta of the Paraná River, Argentina. Mammalia 62: 37-52.

QUINTANA RD AND RABINOVICH JE. 1993. Assessment of capybara (Hydrochoerus hydrochaeris) populations in the wetlands of Corrientes, Argentina. Wetl Ecol Manag 2: $223-230$.

SANTOS SA, DESBIEZ ALJ, MAGALHÃES JA, GARCIA JB AND SOBRINHO AAB. 2010. Descritores epidérmicos de gramíneas: um guia para identificação da dieta de herbívoros usando o programa Delta. Boletim de Pesquisa. Embrapa Pantanal 95: 64.

SCHOENER TW. 1974. Competition and the form of habitat shift. Theor Popul Biol 6: 265-307.

SMITH AR, PRYER KM, SCHUETTPELZ E, KORALL P, SCHNEIDER H AND WOLF PG. 2006. A classification for extant ferns. Taxon 55: 705-731.

SINCLAIR ARE. 1985. Does interspecific competition or predation shape the African ungulate community? J Anim Ecol 54: 899-918.
TOWNSEND CR, BEGON M AND HARPER JL. 2006. Fundamentos em Ecologia, $2^{\mathrm{a}}$ ed., Porto Alegre: Artmed.

WINEMILLER KO AND PIANKA ER. 1990. Organization in natural assemblages of desert lizards and tropical fishes. Ecol Monogr 60: 27-55.

VOETEN MM AND PRINS HHT. 1999. Resource partitioning between sympatric wild and domestic herbivores in the Tarangire region of Tanzania. Oecologia 120: 287-294.

\section{SUPPLEMENTARY MATERIAL}

Table SI - Food importance (IAi\%), frequency of occurrence (FO\%) and numerical abundance (N\%) of families and food items consumed by capybara and nutria, in the Taim wetland, south of Brazil.

Table SII - Food importance (IAi\%) per season, autumn (A), winter (W), spring (S) and summer $\mathrm{Su}$, of families and food items consumed by capybara and nutria, and the Shannon index ( $\left.\mathrm{H}^{\prime}\right)$ for each rodent seasons, in the Taim wetland, south of Brazil. 